\title{
IMPLEMENTASI WASTE ASSESMENT MODEL UNTUK ME NING KATKAN OUTPUT PRODUKSI (STUDI KASUS SEWING LINE PT X)
}

\author{
IMPLEMENTATION OF WASTE ASSESSMENT MODEL TO IMPROVE \\ PRODUCTION OUTPUT (CASE STUDY IN SEWING LINE AT PT X)
}

\author{
Susanti Windari, Achmad Ibrahim Makki* \\ Politeknik STTT Bandung, Bandung, 40272, Indonesia \\ *Alamat email penulis korespondesi : ibrahimmakki@stttekstil.ac.id
}

Tanggal diterima : 15 Februari 2021; direvisi: 15 September 2021 ; disetujui terbit: 15 November 2021

\begin{abstract}
Abstrak
Rendahnya tingkat pencapaian output produksi dapat terjadi karena adanya pemborosan atau waste. Waste ditandai dengan tingginya rework dan reject, serta rendahnya kualitas dan produktivitas kerja. Waste dapat direduksi dengan mengetahui tingkat persentase waste tertinggi dan terendah, sehingga dapat diketahui jenis waste yang paling mempengaruhi timbulnya jenis waste yang lain. Dengan mengidentifikasi jenis waste yang terjadi diharapkan dapat dicari akar penyebab waste dan solusinya sehingga berdampak pada peningkatan output produksi. Waste assessment model (WAM) merupakan metode yang digunakan untuk mengetahui jenis waste yang terjadi pada industri manufaktur. Berdasarkan pendekatan metode WAM pada studi kasus proses penjahitan artikel "01" ditemukan bahwa waste yang paling kritis yaitu waste inappropriate processing. Waste ini diakibatkan oleh tingginya tingkat rework pada bagian kerah dari output yang dihasilkan. Akar penyebab rework pada bagian kerah yaitu tidak adanya alat bantu yang dapat meminimalisir dan memudahkan proses penjahitan kerah. Setelah dilakukan perbaikan tingkat rework menurun $52,13 \%$ yang diikuti dengan meningkatnya output produksi.
\end{abstract}

Kata kunci : Pemborosan, Penjahitan, Waste Assesment Model

\begin{abstract}
The low level of production output achievement can occur due to waste. Waste is characterized by high rework and rejects, low quality and work productivity. Waste can be reduced by knowing the highest percentage levels of waste, so that the types of waste that most influence the emergence of other types of waste can be identified. By identifying the type of waste that occurs, it is hoped that the root causes of waste can be found and a solution so that it has an impact on increasing production output. The Waste assessment model (WAM) is a method used to determine the type of waste that occurs in the manufacturing industry. Based on the WAM method approach in the case study of the sewing process article "01", it was found that the most critical waste was inappropriate processing waste. This waste is caused by the high level of rework on the collar of the output produced. The root cause of rework on the collar is the absence of tools that can minimize and facilitate the process of sewing the collar.After repairs were made, the level of rework decreased $52,13 \%$ and followed by an increase in production output.
\end{abstract}


Keywords : Waste, Sewing Process, Waste Assesment Model

\section{PENDAHULUAN}

Produktivitas kerja adalah kemampuan dalam berproduksi dibandingkan dengan input yang digunakan, seseorang pegawai/karyawan dapat dikatakan produktif apabila mampu menghasilkan barang atau jasa sesuai dengan yang diharapkan dalam waktu yang singkat atau tepat.

Produktivitas memiliki dua dimensi, yaitu pertama efektivitas yang mengarah kepada pencapaian untuk kerja yang maksimal yaitu pencapaian target yang berkaitan dengan kualitas, kuantitas, dan waktu. Kedua yaitu efisiensi yang berkaitan dengan upaya membandingkan input dengan realisasi penggunaannya atau bagaimana pekerjaan tersebut dilaksanakan'1. Bagaimanapun keadaanya perusahaan menginginkan persentase produktivitas sesuai dengan yang telah ditetapkan, jika tidak perusahaan akan mengalami kerugian.

Peningkatan produktivitas dapat dilakukan dengan meningkatkan kualitas input (misalnya melatih tenaga kerja supaya bekerja lebih gesit dan memperbaiki cara kerja), atau memperbaiki proses supaya mengurangi pemborosan (misalnya mengurangi aktivitas yang tidak berorientasi menghasilkan output) ${ }^{2}$.

Pemborosan merupakan segala aktivitas pemakaian sumber daya (resource) yang tidak memberikan nilai tambah. Terdapat 7 tipe waste yang yaitu : over production, defect, unnecessary inventory, inappropriate processing, excessive transportation, waiting, dan unnecessary motion ${ }^{3}$. Semua jenis waste sering terjadi tanpa disadari karena telah dianggap sebagai hal yang sudah biasa, padahal hal tersebut sangat merugikan perusahaan.
Pengurangan waste akan mudah dilakukan jika sudah diketahui jenis waste apa yang terjadi. Untuk itu perlu diadakan identifikasi terhadap semua jenis waste agar dapat diambil langkah yang tepat untuk mereduksi waste tersebut. Proses identifikasi dilakukan pada sewing line dengan nilai rata-rata persentase pancapaian output paling rendah dari standar yang ditetapkan perusahaan. Untuk mengidentifikasi waste secara tepat dapat dilakukan dengan menggunakan tools Waste assessment model (WAM).

Berdasarkan rekapitulasi kuesioner pada stasiun kerja mesin rajut dengan menggunakan pendekatan WAM yang digunakan oleh Suranto (2016) dalam penelitiannya menunjukkan bahwa waste yang paling berpengaruh terhadap waste yang lainnya adalah $P$ atau Ineffective P rocess dengan skor 36 $(16,1 \%)$ dan waste yang paling terpengaruhi yaitu $W$ atau Waiting, D atau Defect dan $M$ atau Ineffective Motion. Berdasarkan penelitian Suranto (2016), dapat disimpulkan bahwa WAM dapat digunakan untuk mengukur hubungan antar waste dalam bentuk persentase dan menunjukkan suatu kemungkinan bahwa satu jenis waste tertentu akan mempengaruhi atau dipengaruhi oleh waste yang lain.

Perhitungan Waste assessment model pada proses produksi filter telah diteliti oleh Sigalingging, dkk(2014) ${ }^{4}$. Intan, dkk (2019) meneliti waste yang ditemukan di unit fisioterapi terdapat lima waste yaitu defect, transportation, waiting, motion dan overprocessing. ${ }^{5}$

Penelitian ini dimaksudkan untuk mengidentifikasi jenis waste yang mempengaruhi dan dipengaruhi oleh jenis waste yang lain pada sewing line 
dengan persentase output yang paling rendah. Adapun tujuan dari penelitian ini adalah untuk meningkatkan output sewing line dengan cara mereduksi waste kritis berdasarkan hasil analisa pendekatan metode WAM.

\section{METODE}

Rendahnya persentase output pada sewing line C4 yang mencapai hanya $59,5 \%$ kemungkinan terjadi karena adanya aktivitas-aktivitas waste yang dilakukan oleh operator selama proses produksi berlangsung. Aktivitas waste perlu dihilangkan agar dapat mencapai target output yang telah ditetapkan.

Waste assessment model merupakan suatu model yang dikembangkan untuk menyederhanakan pencarian dari permasalahan waste untuk mengidentifikasi dalam mengeliminasi waste ${ }^{6}$. Model ini menggambarkan hubungan antar seven waste yakni over production, over processing, inventory, transportation, defects, waiting dan motion. Waste matrix digunakan untuk mengukur hubungan diantara waste dalam bentuk prosentase dan menunjukkan suatu kemungkinan bahwa satu jenis waste tertentu akan mempengaruhi atau dipengaruhi oleh waste yang lain.

Untuk dapat mengetahui jenis waste yang mempengaruhi dan dipengaruhi oleh waste yang lain maka perlu adanya waste yaitu over production, waiting, transportation, ineffective process, inventory, ineffective motion dan defect. Identifikasi waste dilakukan berdasarkan hasil brainstorming, wawancara, dan pengisian lembar kuesioner oleh koresponden yang mengetahui seluk beluk objek pengamatan. Selain itu diskusi juga dilakukan untuk menyatukan persepsi tentang pemahaman terhadap waste dan keterkaitan antar waste menggunakan kriteria pembobotan yang dikembangkan oleh Rawabdeh (2005) yang disesuaikan terlebih dahulu dengan kebutuhan dan kondisi perusahaan 6 .

Koresponden pada penelitian ini terdiri dari kepala administrasi bagian sewing untuk mengetahui sewing line yang tidak mencapai target produksi sebagai indikasi fenomena awal pemborosan, kepala divisi dan kepala bagian sewing yang dianggap mampu menjawab pertanyaan seven waste relationship. Penyebaran waste assessment questionnaire diberikan kepada kepala divisi, kepala regu, ADM dan assisten line. Observasi langsung dilakukan pada sewing line dibawah supervisi kepala divisi dan kepala bagian sebagai narasumber.

Keterkaitan antar waste dianalisis menggunakan waste relationship matrix. Waste relationship matrix merupakan analisis kriteria pengukuran menggunakan suatu matrix. Tiap baris dari matrix menunjukkan hubungan dari suatu waste tertentu terhadap enam waste lainnya. Demikian pula tiap kolom menunjukkan seberapa tingkat tipe waste tertentu akan mempengaruhi waste lainnya ${ }^{6}$.

Setelah diketahui waste yang mempengaruhi dan dipengaruhi oleh jenis waste yang lain selanjutnya melakukan perhitungan skor waste berdasarkan hasil waste assessment questionnaire sehingga diketahui waste dengan peringkat tertinggi hingga terendah. Waste assessment questionnaire dikembangkam untuk mengalokasikan waste yang terjadi pada lini produksi ${ }^{6}$. Kuisioner assessment ini terdiri dari 68 pertanyaan yang berbeda, dimana kuisioner ini bertujuan untuk menentukan waste. Setiap pertanyaan kuisioner merepresentasikan suatu aktivitas, kondisi atau sifat yang dapat 
menimbulkan suatu jenis waste tertentu. Pertanyaan dalam kuisioner tersebut dikategorikan kedalam empat kelompok yaitu man, machine, material dan method.

Kemudian waste dengan peringkat tertinggi dianalisis penyebabnya menggunakan Root cause analysis, yaitu tools yang dapat digunakan untuk memecahkan masalah atau untuk mengidentifikasi peluang peningkatan dengan cara mencari akar permasalahan ${ }^{7}$. tools yang digunakan adalah 5 why's. Metode ini dilakukan dengan mengulang-ulang pertanyaan "mengapa", sampai ditemukan akar penyebab masalah yang dapat diperbaiki. Metode 5 why digunakan untuk menggali suatu kejadian sampai pada akar penyebabnya. Diharapkan dari hasil tersebut dapat diambil langkah yang tepat untuk mereduksi penyebab waste sehingga tingkat persentase output dapat meningkat? .



Gambar 1. Hubungan antar waste ${ }^{6}$

\section{HASIL DAN PEMBAHASAN Seven waste relationship matrix} Semua jenis waste bersifat interdependents, dan berpengaruh terhadap jenis lain. Hubungan antar waste memang sangat kompleks, hal ini disebabkan pengaruh dari tiap waste dapat muncul secara langsung maupun tidak langsung. Hubungan antar jenis waste memiliki bobot yang berbeda ${ }^{6}$. Oleh sebab itu dibutuhkan penilaian untuk mengetahui bobot dari tiap pola hubungan yang terjadi diantara waste tersebut.

Seven waste relation dilakukan untuk mengetahui hubungan keterkaitan antar waste. Proses identifikasi keterkaitan antar waste dilakukan secara diskusi dengan menggunakan kriteria pembobotan yang dikembangkan oleh Rawabdeh (2005) yang disesuaikan terlebih dahulu dengan kebutuhan dan kondisi perusahaan. Diskusi dilakukan dengan kepala supervisor, supervisor dan kepala regu sewing line. Pembobotan bertujuan untuk mengetahui hubungan antar waste, mulai dari absolutely necessary hingga important. Pertanyaan seven waste relationship disajikan dalam Tabel 1.

Dari enam pertanyaan yang ditunjukan pada Tabel 1 akan diajukan untuk masing-masing hubungan antar waste sehingga total terdapat 186 pertanyaan (31 hubungan x 6 pertanyaan). Total skor yang diperoleh dari enam pertanyaan untuk masing-masing hubungan antar waste digunakan untuk mendapatkan nilai total tiap hubungan. Adapun penjelasan hubungan antar waste dapat dilihat pada Tabel 2 . Perhitungan hasil ringkasan dari skor dan tingkat keterkaitan antar waste pada proses penjahitan artikel "01" yang menjadi objek penelitian ini disajikan pada Tabel 3. 
Waste Assessment Questionnare Jumlah pertanyaan dalam Waste Assessment Questionnaire yang disebarkan yaitu sebanyak 25 pertanyaan. Penilaian awal WAQ berdasarkan pada nilai waste yang didapatkan dari WRM. Pertanyaan dibagi menjadi pertanyaan "from" dan "to". Pertanyaan jenis "from" menjelaskan bahwa jenis waste tersebut dapat memicu munculnya jenis waste lainnya berdasarkan WRM. Sedangan pertanyaan jenis "to" menjelaskan bahwa waste yang ada dapat terjadi karena dipengaruhi oleh waste lainnya. Masing-masing pertanyaan memiliki jawaban "Ya", "Sedang" dan "Tidak", jika jawaban "Ya" berarti diindikasikan adanya pemborosan. Jika jawaban "Ya" bernilai 1, jika "Sedang" 0,5 dan jika "Tidak" bernilai 0. Data hasil dari penyebaran waste assessment questionnaire ditunjukan pada tabel 4 .

Tabel 1. Daftar pertanyaan seven waste relationship

\begin{tabular}{|c|c|c|c|}
\hline No & Pertanyaan & Pilihan Jawaban & Skor \\
\hline \multirow{3}{*}{1} & \multirow{3}{*}{$\begin{array}{c}\text { Apakah i mengakibatkan atau } \\
\text { menghasilkan j }\end{array}$} & a. Selalu & 4 \\
\hline & & b. Kadang-kadang & 2 \\
\hline & & c. Jarang & 0 \\
\hline \multirow{3}{*}{2} & \multirow{3}{*}{$\begin{array}{l}\text { Bagaimana hubungan antara } \mathrm{i} \\
\text { dan } \mathrm{j}\end{array}$} & a. Jika i naik, maka j naik & 2 \\
\hline & & b. Jika i naik, maka j tetap & 1 \\
\hline & & c. Tidak tentu tergantung keadaan & 0 \\
\hline \multirow{3}{*}{3} & \multirow{3}{*}{ Dampak j dikarenakan i } & a. Tampak secara langsung \& jelas & 4 \\
\hline & & b. Butuh waktu untuk terlihat & 2 \\
\hline & & c. Tidak terlihat & 0 \\
\hline \multirow{3}{*}{4} & \multirow{3}{*}{$\begin{array}{l}\text { Menghilangkan akibat i terhadap j } \\
\text { dapat dicapai dengan cara .. }\end{array}$} & a. Metode Engineering & 2 \\
\hline & & b. Sederhana dan langsung & 1 \\
\hline & & c. Solusi instruksional & 0 \\
\hline \multirow{7}{*}{5} & \multirow{7}{*}{$\begin{array}{l}\text { Dampak j dikarenakan i } \\
\text { berpengaruh kepada ... }\end{array}$} & a. Kualitas produk & 1 \\
\hline & & b. Produktivitas sumber daya & 1 \\
\hline & & c. Lead time & 1 \\
\hline & & d. Kualitas dan produktivitas & 2 \\
\hline & & e. Kualitas dan lead time & 2 \\
\hline & & f. Produktivitas dan lead time & 2 \\
\hline & & $\begin{array}{l}\text { g. Kualitas, Produktivitas, dan lead } \\
\text { time }\end{array}$ & 4 \\
\hline \multirow{3}{*}{6} & \multirow{3}{*}{$\begin{array}{l}\text { Sebesar apa dampak i terhadap j } \\
\text { akan meningkatkan lead time }\end{array}$} & a. Sangat tinggi & 4 \\
\hline & & b. Sedang & 2 \\
\hline & & c. Rendah & 0 \\
\hline
\end{tabular}

Sumber : Rawabdeh, 2005

Keterangan :

$\mathrm{i}=$ waste yang ingin di identifikasi

$\mathrm{j}=$ waste yang ingin di identifikasi

contoh : Apakah waste overproduction mengakibatkan atau menghasilkan waste inventory 
Tabel 2. Hubungan antar tujuh waste

\begin{tabular}{|c|c|}
\hline Hubungan & Penjelasan \\
\hline O_M & $\begin{array}{l}\text { Produksi yang berlebih menuntun terhadap tingkah laku yang tidak ergonims, yang } \\
\text { mana perilaku tersebut tidak sesuai dengan standar kerja }\end{array}$ \\
\hline O_T & $\begin{array}{l}\text { Produksi yang berlebih menuntun perpindahan yang lebih sering berdasarkan aliran } \\
\text { material yang berlebih }\end{array}$ \\
\hline O_W & $\begin{array}{l}\text { Saat memproduksi lebih, sumber daya akan digunakan lebih lama lagi, demikian } \\
\text { juga pelanggan akan menunggu lebih lama dan antrian menjadi lebih banyak }\end{array}$ \\
\hline I_O & $\begin{array}{l}\text { Semakin banyak material yang disimpan dapat mendorong pekerja untuk bekerja } \\
\text { lebih dengan tujuan untuk meningkatkan keuntungan perusahaan }\end{array}$ \\
\hline I_D & $\begin{array}{l}\text { Meningkatkan persediaan (bahan baku, bahan setengah jadi, dan produk jadi) akan } \\
\text { meningkatkan kemungkinan terjadinya cacat hingga kurangnya perhatian dan } \\
\text { kondisi yang tidak cocok }\end{array}$ \\
\hline I_M & $\begin{array}{l}\text { Meningkatkan persediaan juga akan meningkatkan waktu pencarian, pemilihan, } \\
\text { pengambilan, pemindahan, dan penanganan }\end{array}$ \\
\hline I_T & $\begin{array}{l}\text { Meningkatkan persediaan kadang-kadang akan mengganggu gang, manjadikan } \\
\text { waktu kegiatan produksi melebihi waktu transportasi }\end{array}$ \\
\hline D_O & $\begin{array}{l}\text { Perilaku produksi yang berlebih muncul untuk mengatasi kekurangan part bahkan } \\
\text { kecacatan }\end{array}$ \\
\hline D_I & $\begin{array}{l}\text { Produksi part yang cacat dibutuhkan pengerjaan ulang yang berarti meningkatnya } \\
\text { jumlah barang setengah jadi sebagai wujud dari persediaan }\end{array}$ \\
\hline D_M & Produksi cacat dapat meningkatkan waktu pencarian, pemilihan, pemeriksaan \\
\hline $\mathrm{D}_{-} \mathrm{T}$ & $\begin{array}{l}\text { Memindahkan part yang cacat ke stasiun pengerjaan ulang akan meningkatkan } \\
\text { keseringan transportasi (kembali arah) atau dengan kata lain transportasi yag boros }\end{array}$ \\
\hline D_W & $\begin{array}{l}\text { Pengerjaan ulang akan membutuhkan tempat kerja sehingga part yang baru akan } \\
\text { menunggu untuk diproses }\end{array}$ \\
\hline M_I & $\begin{array}{l}\text { Metode kerja yang tidak sesuai berstandar akan menjadikan jumlah barang } \\
\text { setengah jadi }\end{array}$ \\
\hline M_D & $\begin{array}{l}\text { Kurang terlatihnya dan standarisasi berarti persentase dari kecacatan akan } \\
\text { meningkat }\end{array}$ \\
\hline M_P & $\begin{array}{l}\text { Saat pekerjaan tidak dilakukan berasarkan standar, pemborosan proses akan } \\
\text { meningkat hingga tersedianya jumlah teknologi yang dibutuhkan }\end{array}$ \\
\hline M_W & $\begin{array}{l}\text { Saat standar tidak diatur, akan banyak memakan waktu untuk pencarian, } \\
\text { pengambilan, pemindahan, perakitan, yang haslilnya akan meningkatkan waktu } \\
\text { tunggu part }\end{array}$ \\
\hline $\mathrm{T}_{-} \mathrm{O}$ & $\begin{array}{l}\text { Barang yang diproduksi dari lebih yang dibutuhkan berdasarkan kapasitas sistem } \\
\text { pengangkutan sehingga menimimasi ongkos pemindahan tiap unit }\end{array}$ \\
\hline T_l & $\begin{array}{l}\text { Tidak cukupnya jumlah material handling equipment menjadikan persediaan yang } \\
\text { berlebihan yang dapat mempengaruhi proses lain }\end{array}$ \\
\hline T_D & $\begin{array}{l}\text { Material handling equipment digunakan berdasarkan fungsi dalam pemborosan } \\
\text { transportasi. Tidak cocoknya peralatan material handling kadang kala dapat } \\
\text { menyebabkan kerusakan yang ahirnya dapat menjadi produk caca }\end{array}$ \\
\hline$T_{-} \mathrm{M}$ & $\begin{array}{l}\text { Saat barang ditransportasi kemanapun artinya semakin tinggi kemungkinan dari } \\
\text { pemborosan pergerakan }\end{array}$ \\
\hline T_W & $\begin{array}{l}\text { Jika peralatan material handling tidak cukup berarti barang akan menyebabkan idle } \\
\text { atau menunggu untuk dipindahkan }\end{array}$ \\
\hline $\mathrm{P}_{-} \mathrm{O}$ & $\begin{array}{l}\text { Agar ongkos dapat dikurangi untuk waktu operasi tiap mesinnya, mesin dipaksa } \\
\text { untuk beroperasi sepenuhnya pada jam operasi yang akhirnya mengakibatkan } \\
\text { produksi berlebih }\end{array}$ \\
\hline$P_{-}$ & $\begin{array}{l}\text { Menggabungkan operasi pada satu lini akan menghasilkan secara langsun untuk } \\
\text { mengurangi jumlah barang setengah jadi dikarenakan untuk menghilangkan } \\
\text { buffer/penyangga }\end{array}$ \\
\hline P_D & Jika mesin tidak diperbaiki dengan benar makan barang cacat akan terjadi \\
\hline
\end{tabular}




\begin{tabular}{|c|l|}
\hline Hubungan & \multicolumn{1}{|c|}{ Penjelasan } \\
\hline P_M & $\begin{array}{l}\text { Teknologi yang baru dari beberapa proses dengan kurangnya pelatihan akan } \\
\text { menciptkan pemborosan pergerakan }\end{array}$ \\
\hline P_W & $\begin{array}{l}\text { Saat penggunaan teknologi yang tidak sesuai, waktu pengaturan dan penghentian } \\
\text { yang berulang akan mengakibatkan waktu tunggu yang lebih lama }\end{array}$ \\
\hline W_O & $\begin{array}{l}\text { Saat sebuah mesin menunggu karena pemasok sedang melayani pelanggan lain, } \\
\text { mesin tersebut kadang kala akan dipaksa untuk berproduksi lebih, dan terus } \\
\text { menerus beroperasi }\end{array}$ \\
\hline W_I & $\begin{array}{l}\text { Menunggu berarti ada banyak barang yang dibutuhkan pada suatu titik, apakah itu } \\
\text { bahan baku, barang setengah jadi, atau barang jadi }\end{array}$ \\
\hline W_D & $\begin{array}{l}\text { Menunggu barang mungkin meyebabkan kecacatan selama berada dikondisi yang } \\
\text { tidak cocok }\end{array}$ \\
\hline
\end{tabular}

Keterangan :

$\mathrm{O}=$ Over P roduction

$\mathrm{M}=$ Motion

$\mathrm{P}=\mathrm{P}$ rocess

Sumber : Rawabdeh, 2005

Tabel 3. Tabulasi perhitungan keterkaitan antar waste

\begin{tabular}{|c|c|c|c|}
\hline $\begin{array}{c}\text { Pertanyaan } \\
\text { Hubungan }\end{array}$ & $\begin{array}{c}\text { Total } \\
\text { Score }\end{array}$ & $\begin{array}{c}\text { Pertanyaan } \\
\text { Hubungan }\end{array}$ & $\begin{array}{c}\text { Total } \\
\text { Score }\end{array}$ \\
\hline O-I & 15 & M-W & 17 \\
\hline O-D & 7 & M-P & 17 \\
\hline O-M & 1 & T-O & 8 \\
\hline O-T & 1 & T-I & 10 \\
\hline O-W & 1 & T-D & 8 \\
\hline I-O & 8 & T-M & 16 \\
\hline I-D & 1 & T-W & 15 \\
\hline I-M & 15 & P-O & 1 \\
\hline I-T & 9 & P-I & 1 \\
\hline D-O & 5 & P-D & 10 \\
\hline D-I & 12 & P-M & 15 \\
\hline D-M & 12 & W-M & 7 \\
\hline D-T & 12 & W-O & 1 \\
\hline D-W & 10 & W-I & 10 \\
\hline M-I & 4 & W-D & 3 \\
\hline M-D & 7 & & \\
\hline
\end{tabular}

\section{Waste relationship matrix}

Total skor pada Tabel 3 dikonversikan menjadi huruf untuk mengetahui hubungan keterkaitan antar waste. Tabel konversi menggunakan kategori jenis 58 hubungan yang sama dengan yang dikembangkan Rawabdeh (2005), namun range disesuaikan dengan jumlah pertanyaan yang digunakan. Hasil konversi keterakitan antar waste berdasarkan total skor ditunjukan pada tabel 6 .

$$
\mathrm{T}=\text { Transportation }
$$

Tabel 4 Data hasil dari penyebaran waste assessment questionnaire (WAQ)

\begin{tabular}{|c|c|c|c|}
\hline No & & Hubungan & Rata- \\
\hline 1 & \multirow{5}{*}{$\sum^{\frac{c}{\pi}}$} & To Motion & 0,00 \\
\hline 2 & & From Defect & 0,88 \\
\hline 3 & & From Waiting & 0,50 \\
\hline 4 & & From Inventory & 0,25 \\
\hline 5 & & From Motion & 1,00 \\
\hline 6 & \multirow{8}{*}{$\begin{array}{l}\bar{\pi} \\
\bar{d} \\
\frac{\pi}{\Sigma} \\
\sum\end{array}$} & From Defect & 1,00 \\
\hline 7 & & From Motion & 1,00 \\
\hline 8 & & From Defect & 0,88 \\
\hline 9 & & From Waiting & 0,25 \\
\hline 10 & & To Motion & 0,00 \\
\hline 11 & & From Transportation & 0,00 \\
\hline 12 & & To Motion & 0,00 \\
\hline 13 & & From Waiting & 0,75 \\
\hline 14 & \multirow{3}{*}{$\begin{array}{l}\overline{\bar{c}} \\
\bar{U} \\
\bar{\Sigma}\end{array}$} & From Waiting & 0,75 \\
\hline 15 & & From Waiting & 1,00 \\
\hline 16 & & To Motion & 1,00 \\
\hline 17 & \multirow{6}{*}{ 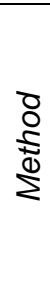 } & To Motion & 0,25 \\
\hline 18 & & From Defect & 0,63 \\
\hline 19 & & To Waiting & 0,00 \\
\hline 20 & & From Process & 0,50 \\
\hline 21 & & To Transportation & 0,00 \\
\hline 22 & & To Motion & 1,00 \\
\hline 23 & \multirow{3}{*}{$\begin{array}{l}\frac{\Gamma}{d} \\
\sum \\
\Sigma\end{array}$} & From Waiting & 0,50 \\
\hline 24 & & From Motion & 1,00 \\
\hline 25 & & From Over Production & 0,75 \\
\hline
\end{tabular}


Tabel 5. Konversi rentang skor keterkaitan antar waste

\begin{tabular}{|c|c|c|}
\hline Range & J enis Hubungan & Simbol \\
\hline $12-14$ & Absolutely necessary & $\mathrm{A}$ \\
\hline $9-11$ & Especially Important & $\mathrm{E}$ \\
\hline $6-8$ & Important & $\mathrm{I}$ \\
\hline $3-5$ & Ordinary Closeness & $\mathrm{O}$ \\
\hline $1-2$ & Unimportant & $\mathrm{U}$ \\
\hline 0 & No relation & $\mathrm{X}$ \\
\hline
\end{tabular}

Tabel 6. Keterkaitan antar waste

\begin{tabular}{|c|c|c|}
\hline $\begin{array}{l}\text { Pertanyaan } \\
\text { Hubungan }\end{array}$ & $\begin{array}{l}\text { Total } \\
\text { Score }\end{array}$ & $\begin{array}{c}\text { Tingkat } \\
\text { Keterkaitan }\end{array}$ \\
\hline O-I & 15 & $E$ \\
\hline O-D & 7 & $\mathrm{O}$ \\
\hline O-M & 1 & $U$ \\
\hline O-T & 1 & $U$ \\
\hline O-W & 1 & U \\
\hline $1-O$ & 8 & 0 \\
\hline I-D & 1 & U \\
\hline I-M & 15 & $E$ \\
\hline I-T & 9 & 1 \\
\hline $\mathrm{D}-\mathrm{O}$ & 5 & 0 \\
\hline D-I & 12 & 1 \\
\hline D-M & 12 & 1 \\
\hline D-T & 12 & 1 \\
\hline D-W & 10 & 1 \\
\hline M-I & 4 & $U$ \\
\hline M-D & 7 & 0 \\
\hline$M-W$ & 17 & A \\
\hline$M-P$ & 17 & A \\
\hline T-O & 8 & 0 \\
\hline T-I & 10 & 1 \\
\hline T-D & 8 & $\mathrm{O}$ \\
\hline T-M & 16 & $E$ \\
\hline T-W & 15 & $E$ \\
\hline $\mathrm{P}-\mathrm{O}$ & 1 & U \\
\hline P-I & 1 & U \\
\hline P-D & 10 & 1 \\
\hline P-M & 15 & $E$ \\
\hline W-M & 7 & $\mathrm{O}$ \\
\hline W-O & 1 & U \\
\hline W-I & 10 & 1 \\
\hline W-D & 3 & $U$ \\
\hline
\end{tabular}

Berdasarkan hasil keterkaitan antar waste pada Tabel 6 maka dapat dibuat waste relationship matrix dari relasi antar waste yang kemudian dilakukan konversi nilai dengan acuan yang diberikan oleh Rawabdeh (2005), yakni $A=10 ; E=8 ; I=6 ; O=4 ; U=2$ dan $X=0$ dan dilakukan penyederhanaan matrix sehingga dikonversikan kedalam bentuk persentase.
Tabel 7 merupakan waste matrix value hasil konversi waste relationship matrix pada proses produksi artikel "01". Berdasarkan Tabel 7, nilai dari from defect dan from transportation memiliki persentase yang paling besar, yakni berturut-turut $19,13 \%$ dan 17,39\%, yang berarti bahwa waste defect dan waste transportation jika terjadi, maka memiliki pengaruh yang cukup besar untuk dapat menimbulkan atau menyebabkan waste yang lain. Selain itu, nilai to motion dan to inventory memiliki persentase yang paling besar yakni berturut-turut $20 \%$ dan 17,39 \%. Hal ini dapat mengindikasikan bahwa waste motion dan waste inventory merupakan waste yang paling banyak diakibatkan oleh waste yang lain.

\section{Waste Assessment Model}

Tahapan cara untuk mengukur peringkat waste dimulai dengan menghitung dan mengelompokkan jumlah pertanyaan kuisioner berdasarkan jenis pertanyaan "from" dan "to" pada Tabel 8. Kemudian memasukkan nilai awal untuk tiap kuisioner berdasarkan waste relationship matrix. Tahapan selanjutnya membagi tiap nilai awal dalam satu baris dengan jumlah pertanyaan yang dikelompokkan (Ni) untuk menghilangkan efek dari variasi jumlah pertanyaan setiap jenis pertanyaan. Serta dilakukan perhitungan total skor (Sj) dan frekuensi nya $(\mathrm{Fj})$.

Dari hasil waste assessment questionnaire, rata-rata hasil skor digunakan sebagai bobot atau weight untuk menghitung nilai yang baru, serta menghitung total skor (sj) dan frekuensi (fj) yang baru

Tahapan terakhir dari Waste assessment model adalah menghitung indikator awal untuk tiap waste $(Y j)$, menghitung nilai final waste factor $(\mathrm{Yj}$ 
final) dengan memasukkan faktor probabilitas pengaruh antar jenis waste $(\mathrm{Pj})$ berdasarkan total "from" dan "to" pada WRM. Kemudian menghitung persentase bentuk final waste factor yang diperoleh sehingga bisa diketahui peringkat level dari masing-masing waste.

Tabel 7. Waste matrix value

\begin{tabular}{|c|c|c|c|c|c|c|c|c|c|}
\hline $\mathrm{F} / \mathrm{T}$ & $\mathrm{O}$ & $\mathrm{I}$ & $\mathrm{D}$ & $\mathrm{M}$ & $\mathrm{T}$ & $\mathrm{P}$ & $\mathrm{W}$ & score & $\%$ \\
\hline $\mathrm{O}$ & 10 & 8 & 4 & 2 & 2 & 0 & 2 & 28 & 12,17 \\
\hline $\mathrm{I}$ & 4 & 10 & 2 & 8 & 6 & 0 & 0 & 30 & 13,04 \\
\hline $\mathrm{D}$ & 4 & 6 & 10 & 6 & 6 & 6 & 6 & 44 & 19,13 \\
\hline $\mathrm{M}$ & 0 & 2 & 4 & 10 & 0 & 10 & 10 & 36 & 15,66 \\
\hline $\mathrm{T}$ & 4 & 6 & 4 & 8 & 10 & 0 & 8 & 40 & 17,39 \\
\hline $\mathrm{P}$ & 2 & 2 & 6 & 8 & 0 & 10 & 0 & 28 & 12,18 \\
\hline $\mathrm{W}$ & 2 & 6 & 2 & 4 & 0 & 0 & 10 & 24 & 10,43 \\
\hline & 26 & 40 & 32 & 46 & 24 & 26 & 36 & 230 & 100 \\
\hline$\%$ & 11,31 & 17,39 & 13,21 & 20 & 10,44 & 11,30 & 15,65 & 100 & \\
\hline
\end{tabular}

Tabel 8. Jumlah jenis pertanyan F rom dan

\begin{tabular}{|c|c|c|}
\hline NO & Jenis Pertanyaan & Total (Ni) \\
\hline 1 & From Defect & 4 \\
\hline 2 & From Waiting & 6 \\
\hline 3 & From Inventory & 1 \\
\hline 4 & From Motion & 3 \\
\hline 5 & From Transportation & 1 \\
\hline 6 & From Process & 1 \\
\hline 7 & To Motion & 6 \\
\hline 8 & To Waiting & 1 \\
\hline 9 & To Transportation & 1 \\
\hline 10 & From Over Production & 1 \\
\hline & Jumlah Pertanyaan & 25 \\
\hline
\end{tabular}

Hasil final waste factor akan didiskusikan kembali dengan kepala divisi untuk menentukan waste yang akan direduksi. Selain itu langkah ini juga bertujuan untuk menyamakan persepsi terhadap waste yang terjadi dan perlu adanya langkah-langkah perbaikan agar dapat mereduksi waste sehingga berdampak pada kenaikan output produksi.

\section{Analisis Penyebab Terjadinya Waste Kritis Menggunakan Tools 5 Why's}

Setelah diketahui waste dengan tingkat persentase tertinggi langkah selanjutnya yaitu mencari akar penyebab terjadinya waste. Pencarian akar permasalahan ini dilakukan untuk mengambil langkah perbaikan yang tepat sehingga berdampak pada meningkatnya output produksi artikel "01". Waste kritis tertinggi yaitu waste Inappropriate Processing.

Berdasarkan hasil perhitungan WAQ waste Inappropriate Processing merupakan waste yang paling tinggi persentasenya. Waste tersebut merupakan waste disebabkan oleh proses kerja yang dilaksanakan dengan menggunakan peralatan, prosedur atau sistem yang tidak sesuai dengan pendekatan yang lebih simpel dan lebih efektif3. Waste ini dapat pula terjadi akibat penggunaan metode atau urutan kerja yang tidak tepat, proses yang belum terstandar, product defect yang tinggi, dan variasi metode yang dilakukan operator. Berikut ini merupakan analisis 5 Why untuk mencari akar permasalahan waste 
Tabel 9. Nilai pertanyaan dibagi Ni dan jumlah Skor (Sj) dan Frekuensi (Fj)

\begin{tabular}{|c|c|c|c|c|c|c|c|c|c|c|}
\hline \multirow{2}{*}{ No } & \multirow{2}{*}{ Kategori } & \multirow{2}{*}{ Hubungan } & \multirow{2}{*}{$\mathrm{Ni}$} & \multicolumn{7}{|c|}{ Nilai awal untuk tiap jenis pertanyaan } \\
\hline & & & & $\mathrm{O}$ & 1 & D & M & $\mathrm{T}$ & $\mathrm{P}$ & W \\
\hline 1 & Man & To Motion & 6 & 0,33 & 1,33 & 1,00 & 1,67 & 1,33 & 1,33 & 0,67 \\
\hline 2 & & From Defect & 4 & 1,00 & 1,50 & 2,50 & 1,50 & 1,50 & 1,50 & 1,50 \\
\hline 3 & & From Waiting & 6 & 0,33 & 1,00 & 0,33 & 0,67 & 0,00 & 0,00 & 1,67 \\
\hline 4 & & From Inventory & 1 & 4,00 & 10,00 & 2,00 & 8,00 & 6,00 & 0,00 & 0,00 \\
\hline 5 & & From Motion & 3 & 0,00 & 0,67 & 1,33 & 3,33 & 0,00 & 3,33 & 3,33 \\
\hline 6 & Material & From Defect & 4 & 1,00 & 1,50 & 2,50 & 1,50 & 1,50 & 1,50 & 1,50 \\
\hline 7 & & From Motion & 3 & 0,00 & 0,67 & 1,33 & 3,33 & 0,00 & 3,33 & 3,33 \\
\hline 8 & & From Defect & 4 & 1,00 & 1,50 & 2,50 & 1,50 & 1,50 & 1,50 & 1,50 \\
\hline 9 & & From Waiting & 6 & 0,33 & 1,00 & 0,33 & 0,67 & 0,00 & 0,00 & 1,67 \\
\hline 10 & & To Motion & 6 & 0,33 & 1,33 & 1,00 & 1,67 & 1,33 & 1,33 & 0,67 \\
\hline 11 & & $\begin{array}{c}\text { From } \\
\text { Transportation }\end{array}$ & 1 & 4,00 & 6,00 & 4,00 & 8,00 & 10,00 & 0,00 & 8,00 \\
\hline 12 & & To Motion & 6 & 0,33 & 1,33 & 1,00 & 1,67 & 1,33 & 1,33 & 0,67 \\
\hline 13 & & From Waiting & 6 & 0,33 & 1,00 & 0,33 & 0,67 & 0,00 & 0,00 & 1,67 \\
\hline 14 & Machine & From Waiting & 6 & 0,33 & 1,00 & 0,33 & 0,67 & 0,00 & 0,00 & 1,67 \\
\hline 15 & & From Waiting & 6 & 0,33 & 1,00 & 0,33 & 0,67 & 0,00 & 0,00 & 1,67 \\
\hline 16 & & To Motion & 6 & 0,33 & 1,33 & 1,00 & 1,67 & 1,33 & 1,33 & 0,67 \\
\hline 17 & Method & To Motion & 6 & 0,33 & 1,33 & 1,00 & 1,67 & 1,33 & 1,33 & 0,67 \\
\hline 18 & & From Defect & 4 & 1,00 & 1,50 & 2,50 & 1,50 & 1,50 & 1,50 & 1,50 \\
\hline 19 & & To Waiting & 1 & 2,00 & 0,00 & 6,00 & 10,00 & 8,00 & 0,00 & 10,00 \\
\hline 20 & & From Process & 1 & 2,00 & 2,00 & 6,00 & 8,00 & 0,00 & 10,00 & 0,00 \\
\hline 21 & & $\begin{array}{c}\text { To } \\
\text { Transportation }\end{array}$ & 1 & 2,00 & 6,00 & 6,00 & 0,00 & 10,00 & 0,00 & 0,00 \\
\hline 22 & & To Motion & 6 & 0,33 & 1,33 & 1,00 & 1,67 & 1,33 & 1,33 & 0,67 \\
\hline 23 & Material & From Waiting & 6 & 0,33 & 1,00 & 0,33 & 0,67 & 0,00 & 0,00 & 1,67 \\
\hline 24 & & From Motion & 3 & 0 & 0,67 & 1,33 & 3,33 & 0,00 & 3,33 & 3,33 \\
\hline 25 & & $\begin{array}{l}\text { From Over } \\
\text { Production }\end{array}$ & 1 & 10 & 8,00 & 4,00 & 2,00 & 2,00 & 0,00 & 2,00 \\
\hline \multicolumn{4}{|c|}{ Total Skor (Sj) } & 32 & 54 & 50 & 66 & 50 & 34 & 50 \\
\hline \multicolumn{4}{|c|}{ Frekuensi (Fj) } & 22 & 24 & 25 & 24 & 15 & 14 & 22 \\
\hline
\end{tabular}

Tabel 10. Hasil total skor (sj) dan Frekuensi (fj) hasil kali dengan Weight

\begin{tabular}{|c|c|c|c|c|c|c|c|c|c|}
\hline Kategori & Hubungan & Weight & $\mathrm{O}$ & $\mathrm{I}$ & $\mathrm{D}$ & $\mathrm{M}$ & $\mathrm{T}$ & $\mathrm{P}$ & $\mathrm{W}$ \\
\hline Man & To Motion & 0,00 & 0,00 & 0,00 & 0,00 & 0,00 & 0,00 & 0,00 & 0,00 \\
\hline & From Defect & 0,88 & 0,88 & 1,31 & 2,19 & 1,31 & 1,31 & 1,31 & 1,31 \\
\hline & From Waiting & 0,50 & 0,17 & 0,17 & 0,17 & 0,33 & 0,00 & 0,00 & 0,83 \\
\hline & From Inventory & 0,25 & 1,00 & 2,50 & 0,50 & 2,00 & 1,50 & 0,00 & 0,00 \\
\hline & From Motion & 1,00 & 0,00 & 1,33 & 1,33 & 3,33 & 0,00 & 3,33 & 3,33 \\
\hline Material & From Defect & 1,00 & 1,00 & 1,50 & 2,50 & 1,50 & 1,50 & 1,50 & 1,50 \\
\hline & From Motion & 1,00 & 0,00 & 1,33 & 1,33 & 3,33 & 0,00 & 3,33 & 3,33 \\
\hline & From Defect & 0,88 & 0,88 & 1,31 & 2,19 & 1,31 & 1,31 & 1,31 & 1,31 \\
\hline & From Waiting & 0,25 & 0,08 & 0,08 & 0,08 & 0,17 & 0,00 & 0,00 & 0,42 \\
\hline & To Motion & 0,00 & 0,00 & 0,00 & 0,00 & 0,00 & 0,00 & 0,00 & 0,00 \\
\hline & From Transportation & 0,00 & 0,00 & 0,00 & 0,00 & 0,00 & 0,00 & 0,00 & 0,00 \\
\hline
\end{tabular}




\begin{tabular}{|c|c|c|c|c|c|c|c|c|c|}
\hline Kategori & Hubungan & Weight & $\mathrm{O}$ & $\mathrm{I}$ & $\mathrm{D}$ & $\mathrm{M}$ & $\mathrm{T}$ & $\mathrm{P}$ & $\mathrm{W}$ \\
\hline & To Motion & 0,00 & 0,00 & 0,00 & 0,00 & 0,00 & 0,00 & 0,00 & 0,00 \\
\hline & From Waiting & 0,75 & 0,25 & 0,25 & 0,25 & 0,50 & 0,00 & 0,00 & 1,25 \\
\hline Machine & From Waiting & 0,75 & 0,25 & 0,75 & 0,25 & 0,50 & 0,00 & 0,00 & 1,25 \\
\hline & From Waiting & 1,00 & 0,33 & 0,33 & 0,33 & 0,67 & 0,00 & 0,00 & 1,67 \\
\hline & To Motion & 1,00 & 0,33 & 1,33 & 1,00 & 1,67 & 1,33 & 1,33 & 0,67 \\
\hline Method & To Motion & 0,25 & 0,08 & 0,25 & 0,25 & 0,42 & 0,33 & 0,33 & 0,17 \\
\hline & From Defect & 0,63 & 0,63 & 0,94 & 1,56 & 0,94 & 0,94 & 0,94 & 0,94 \\
\hline & To Waiting & 0,00 & 0,00 & 0,00 & 0,00 & 0,00 & 0,00 & 0,00 & 0,00 \\
\hline & From Process & 0,50 & 1,00 & 1,00 & 3,00 & 4,00 & 0,00 & 5,00 & 0,00 \\
\hline & To Transportation & 0,00 & 0,00 & 0,00 & 0,00 & 0,00 & 0,00 & 0,00 & 0,00 \\
\hline & To Motion & 1,00 & 0,33 & 1,33 & 1,00 & 1,67 & 1,33 & 1,33 & 0,67 \\
\hline Material & From Waiting & 0,50 & 0,17 & 0,17 & 0,17 & 0,33 & 0,00 & 0,00 & 0,83 \\
\hline & From Motion & 1,00 & 0,00 & 0,67 & 1,33 & 3,33 & 0,00 & 3,33 & 3,33 \\
\hline & From Over Production & 0,75 & 7,50 & 3,00 & 3,00 & 1,50 & 1,50 & 0,00 & 1,50 \\
\hline & Total skor sj & & 14,88 & 19,56 & 22,44 & 28,81 & 11,06 & 23,06 & 24,31 \\
\hline & Frekuensi fj & & 15 & 19 & 19 & 19 & 9 & 11 & 17 \\
\hline
\end{tabular}

Tabel 11. Rekapitulasi Hasil Waste Assessment

\begin{tabular}{|c|c|c|c|c|c|c|c|r|}
\hline & $\mathbf{O}$ & $\mathbf{I}$ & $\mathbf{D}$ & $\mathbf{M}$ & $\mathbf{T}$ & $\mathbf{P}$ & $\mathbf{W}$ & Total \\
\hline score $(\mathrm{Yj})$ & 0,32 & 0,29 & 0,34 & 0,35 & 0,13 & 0,53 & 0,38 & 2,33 \\
\hline Pj Factor & 10,59 & 48,55 & 45,42 & 93,98 & 24,19 & 70,19 & 34,22 & 327,14 \\
\hline Final Result (Yj Final) & 3,36 & 13,92 & 15,49 & 32,48 & 3,21 & 37,41 & 12,86 & 118,73 \\
\hline Final Result (\%) & $2,8 \%$ & $12 \%$ & $13 \%$ & $27 \%$ & $2,7 \%$ & $32 \%$ & $11 \%$ & $100 \%$ \\
\hline Rank & 7 & 4 & 3 & 2 & 6 & 1 & 5 & \\
\hline
\end{tabular}

.Tabel 3. 1 Analisis 5 Why waste Inappropriate Processing

\begin{tabular}{|c|c|c|c|c|c|}
\hline Waste & Why 1 & Why 2 & Why 3 & Why 4 & Why 5 \\
\hline $\begin{array}{l}\text { Inappro- } \\
\text { priate } \\
\text { Proces- } \\
\text { sing }\end{array}$ & $\begin{array}{l}\text { Ba- } \\
\text { nyak- } \\
\text { nya } \\
\text { rework } \\
\text { pada } \\
\text { bagian } \\
\text { leher }\end{array}$ & $\begin{array}{l}\text { jahitan } \\
\text { mele- } \\
\text { set } \\
\text { dan } \\
\text { tidak } \\
\text { lurus }\end{array}$ & $\begin{array}{l}\text { Tidak } \\
\text { ada- } \\
\text { nya } \\
\text { alat } \\
\text { bantu }\end{array}$ & & \\
\hline
\end{tabular}

Tahap perancangan usulan perbaikan berisi rekomendasi perbaikan dari hasil analisis dan pengolahan data yang telah dilakukan sebelumnya. Fokus perbaikan yang dilakukan yaitu pada waste kritis yang menyebabkan target output produksi tidak tercapai. Setelah diketahui akar penyebab waste kritis langkah selanjutnya yaitu membuat rancangan usulan perbaikan.
Akar masalah dari waste yang terjadi adalah tidak adanya alat bantu. Rancangan perbaikan yang dilakukan yaitu membuat alat bantu yang dapat memudahkan proses penjahitan kerah

\section{KESIMPULAN DAN SARAN}

Waste merupakan kegiatan yang tidak bernilai tambah yang harus direduksi. Kegiatan yang tidak bernilai tambah akan merugikan perusahaan. Waste bersifat interdependent yang saling bergantung satu sama lain. Dengan demikian untuk dapat mereduksi waste terlebih dahulu yang perlu dilakukan adalah dengan mencari tahu hubungan antar waste yang tarjadi di lapangan dengan menggunakan pendekatan metode Waste relationship matrix (WRM). Hubungan waste tersebut yaitu 
waste defect dapat meningkatkan waktu pencarian, pemilihan dan proses pemeriksaan. Sedangakan dari hasil peringkat waste kritis yang diperoleh dengan menggunakan metode WAM didapat bahwa waste kritis yaitu waste inappropriate processing

Hasil pendekatan dengan metodemetode tersebut sesuai dengan keadaan yang terjadi pada perusahaan yang diamati. Dimana defect pada bagian kerah menyebabkan waktu proses pemeriksaan meningkat dan berdampak pada banyaknya pekerjaan yang harus diperbaiki rework dan diikuti dengan penurunan output. Langkah selanjutnya untuk dapat meningkatkan output adalah dengan mencari akar permasalahan waste dengan menggunakan root cause analysis.

Penurunan rework terjadi karena adanya proses reduksi waste inappropriate processing pada unsurunsur penyebab waste. Unsur penyebab terjadinya wastetersebut adalah karena faktor metode. Pada saat proses pengerjaan kerah, operator tidak menggunakan menggunakan alat bantu yang dapat meminimalisir terjadinya jahitan meleset dan tidak rata.

Berdasarkan dari hasil pemecahan permasalahan yang terjadi pada perusahaan amatan ditemukan bahwa waste dengan peringkat tertinggi yaitu waste inappropriate processing. Waste ini terjadi karena tidak adanya alat bantu yang pada proses pengerjaan kerah.

Setelah dilakukan penerapan perbaikan yaitu dengan pemasangan alat bantu berupa pembatas pada meja jahit oleh operator didapatkan hasil penurunan rework bagian kerah. Terjadi penurunan rework yaitu dari $44,5 \%$ menjadi $21,3 \%$ dari total output yang dihasilkan. Dan begitu juga dengan output produksi yang mengalami peningkatan yang signifikan.

Membandingkan metode waste assessment method dengan metode lainnya dalam upaya peningkatan produktivitas dapat dilakukan untuk penelitian selanjutnya. 


\section{DAFTAR PUSTAKA}

1. Umar, H. R iset Sumber Daya Manusia dalam Organisasi. (PT Gramedia Pustaka Utama, 2004).

2. Martono, R. V. Analisis Produktivitas \& E fisiensi. (Gramedia Pustaka Utama, 2019).

3. Hines, P. \& Taylor, D. Going lean : a guide to implementation. (Lean Enterprise Research Centre, 2000).

4. Sigalingging, E. A., Tama, I. P. \& Riawati, L. Penerapan Lean Manufacturing untuk Mereduksi Waste pada Produksi Filter Rokok dengan Wam dan Metode Taguchi (Studi Kasus Pada PT Essentra, Sidoarjo). J . Rekayasa dan Manaj. Sist. Ind. 2, 495-505 (2014).

5. Sari, I. permata, Iftadi, I. \& Astuti, R. D. Identifikasi Waste Dengan Metode Waste Assesment Model (WAM) Di Unit Fisioterapi RSUD Kabupaten Karanganyar. 1 st Conf. Ind. Eng. Halal Ind. 55-60 (2019).

6. Rawabdeh, I. A. A model for the assessment of waste in job shop environments. Int. J . O per. P rod. Manag. 25, 800-822 (2005).

7. Barsalou, M. A. R oot Cause Analysis A S tep-By-Step Guide to Using the Right Tool at the Right Time. Taylor and Francis (2015). 